\title{
Photonics at TVI Community College: a critical rung in New Mexico's photonics education ladder
}

John Bellum, Srini Vasan, Joel Gellman

John Bellum, Srini Vasan, Joel Gellman, "Photonics at TVI Community College: a critical rung in New Mexico's photonics education ladder," Proc. SPIE 9663, Eighth International Topical Meeting on Education and Training in Optics and Photonics, 96630D (6 October 2003); doi: 10.1117/12.2208377

SPIE Event: Eighth International Topical Meeting on Education and Training in Optics and Photonics, 2003, Tucson, Arizona, United States 


\title{
Photonics at TVI Community College - a critical rung in New Mexico's photonics education ladder
}

\author{
John Bellum, Srini Vasan and Joel Gellman \\ Technologies Department, Albuquerque TVI Community College, 525 Buena Vista SE, Albuquerque, NM 87106 \\ telephone: 505-224-3340; fax: 505-224-3341; e-mail: igellman@tvi.edu
}

\begin{abstract}
The place of Albuquerque TVI Community College in the ladder of photonics education in New Mexico is presented. TVI has offered photonics courses since the late 70s. These courses formed the first rung of what has developed into a ladder of photonics educational opportunities in New Mexico, ranging from middle and high school initiatives to university programs. Details of how TVI established its current Photonics Technology Program and a description of this program are presented. Two key elements of success in photonics education are emphasized - excellence in teaching traditional and non-traditional students of diverse educational backgrounds, and involvement and feedback from industry in shaping educational and training programs in photonics.

(C2003 Optical Society of America

OCIS codes: (000.2060) Education; (000.4930) Other topics of general interest
\end{abstract}

\section{Summary}

Albuquerque Technical Vocational Institute (TVI) has a long history of providing post secondary education and training in laser and optical technologies. Dating back to the late 70s, TVI launched a Laser and Electro-Optical Technology Program to meet the needs for qualified technical professionals in the then emerging laser industries. Close ties with industry have continued to be a hallmark of TVI's post secondary program in photonics technology education. TVI holds the honor of having formed the initial rung in what has now developed into a Photonics Ladder of educational opportunities for New Mexicans. That this initial rung of photonics education programs in New Mexico is a solid community college program combined with close ties to industry holds much significance. TVI aspires to continue as a model of educational excellence and service to the photonics community.

TVI established its current Photonics Technology Program in an effort to reinforce its curriculum with recent cutting edge developments in laser, optics and fiber optics technologies. In establishing this program, three years ago TVI conducted a needs assessment within the photonics community. This provided vital information to guide the choice of curriculum and also provided a vital involvement of the photonics industry in shaping the program. A questionnaire survey was sent out to 180 candidates from industry, laboratories and universities. The survey sought responses in the following areas: importance of TVI to have a Photonics Technology program; skills required of the program graduates; current number of photonics technicians and the number of annual new hires; entry level wages of photonics technicians; ways in which industry would support a program; preferred duration of a program; and type of program, certificate or degree, needed. Eighty-four completed the questionnaire survey, which was conducted via the Internet. The results showed that an overwhelming $97 \%$ of respondents indicated a need for the TVI Photonics Technology program, while 75\% perceived a shortage of photonics technicians and technical training in the Southwest. The estimated entry level hourly wage for a TVI graduate with a certificate was $\$ 11$, while that for an associate degree holder was $\$ 14$. Among the respondents, $79 \%$ believed that a program offering an Associates degree was needed. There are currently at least 19 corporations in the Albuquerque area that employ full time photonics technicians. CVI Laser Corp. and Sandia National Laboratories are the largest of these, each employing more than 100 full time technicians. In addition to this overall information, TVI was able to identify an Advisory Committee of representatives from the photonics industry who were willing to help guide and provide feedback regarding photonics issues and needs facing industry. Local companies such as CVI Laser Corp., Emcore, F2 Associates Inc., Logicon, Optomec, and R-Cubed Inc., as well as the University of New Mexico's Center for High Technology Materials, provided strong letters of support for a photonics technology program.

Once TVI clearly established the need for a Photonics Technology program, it conducted a comprehensive skills and competencies survey which elicited 22 responses. Task ratings were analyzed and the tasks ranked. Cross correlation of the task ratings with the curriculum enabled the determination of specific courses and competencies to be included in the program. As a result, ten of the courses deemed relevant by the National Skills Standards were 
found to be pertinent to the Albuquerque area. Among these, TVI offers Introduction to Photonics and Safety, Optics, Electronics, Laser Systems, and Fiber Optics. Advanced level courses in laser systems and fiber optics culminating in a capstone Photonics Project were additionally chosen, along with digital electronics and semiconductor devices as well as courses in humanities, science and math, to be included in the curriculum for the Associate of Applied Science Degree in Photonics Technology.

With its focus on excellent teaching combined with involvement and feedback from industry, TVI's Photonics Technology Program plays a key, pivotal role in New Mexico's Photonics Educational Ladder. It is a bridge in this ladder linking its secondary-level middle and high school programs and university programs, and also linking photonics education to industry needs. TVI's program has been able to serve as this important bridge because it, like all good community college programs must be, is very versatile so as to effectively engage and equip a wide range of students, from those fresh out of high school to non-traditional adult students making career transitions. This requires that instructors be able to identify the knowledge base of a student, regardless of the student's educational background, and use that knowledge base as a starting point to lead the student to a practical, hands-on understanding of state-of-the-art photonics technology. In recognizing the importance of such excellent instruction and of industry feedback, TVI's Photonics Technology Program strives to continue serving as the critical bridge in New Mexico's Photonics Technology Ladder, preparing students from diverse backgrounds to either directly enter the photonics industry as productive employees or to go on to eventual undergraduate or graduate level studies in laser, optical and photonics science and engineering. 